\title{
The discovery of the association between blue asbestos and mesotheliomas and the aftermath
}

\author{
J C Wagner
}

\begin{abstract}
As this is the 30th anniversary of the publication of our paper "Diffuse pleural mesotheliomas and asbestos exposure in the north west Cape Province," 1 and 1 December 1990 is the first anniversary of John Gilson's death, I think it is appropriate to submit this paper. It covers the background of the discovery of the series of mesotheliomas in the north western region of the Cape Province, and the subsequent publication, which has become the most cited paper in industrial medicine. It was John Gilson who directed the next phase, which substantiated this discovery. He clarified the situation in his summary of the report to the director of the International Agency for Research in Cancer in 1972..$^{2-4}$ This I have quoted in full and have had the temerity to update to 1990 . I am sure that many will want to elaborate these views, and I hope that they will submit their opinions to this journal.
\end{abstract}

The first diffuse pleural mesothelioma of our series came for necropsy examination in February 1956. The clinical features of this case were described by Martiny in $1956 .{ }^{5}$ At the time of his death the case, a Bantu man, was thought to have had tuberculous pleurisy. He had not responded to chemotherapy. He had developed a pleural effusion, and attempts at aspiration were not successful because of the "sticky" nature of the fluid. It was thought that he had developed an empyema, which was considered to be the cause of death.

On opening the thoracic cavity, I was amazed to find a huge gelatinous tumour (fig 1), which filled the right thoracic cavity, and infiltrated into the parietal pericardium. The mediastinum was displaced, with congestion of the left lung. On slicing into the mass a greatly contracted right lung was found. I had never seen a mesothelioma but had read brief descriptions of these tumours in the larger tomes on pathology. I was also aware that there was a controversy as to whether these tumours existed or whether they were all secondary tumours from other primary sites and I consulted the professor of pathology at the

Late of the MRC Pneumoconiosis Unit. Present address 59 Coombe Valley Rd, Preston, Weymouth, Dorset DT3 6NL

J C Wagner
University of Witwatersrand, B J P Becker. We first undertook a detailed study to exclude any primary from another site, and as we found none, he agreed that it was probably a diffuse malignant mesothelioma of the pleura; we carried out a full histological and histochemical study of the tissues, which confirmed this diagnosis.

As I was preparing the case for demonstration at the local thoracic group meeting, my assistant Mr D E Munday suggested that we should take sections from the underlying lung tissue, and we were surprised to find occasional clumps of asbestos bodies in the air spaces of the lung, but there was no evidence of an interstitial reaction. Olaf Martini and I presented the case with the clinical, radiological, and pathological features. At this meeting was $\mathrm{Mr}$ Libro Fatti, chairman of the thoracic surgery department. A week later, Fatti received a request to see a patient in Kimberly, the town at the centre of the diamond mining industry (see fig 2). While in Kimberly, Mr Fatti was consulted by Dr Kit Sleggs, who was the superintendant of the West End Tuberculosis Hospital. (During the second world war the Royal Air Force had established an air training school at Kimberly for Royal Air Force and Commonwealth pilots, and had built a hospital that was presented to the South African Government after the war.) It was

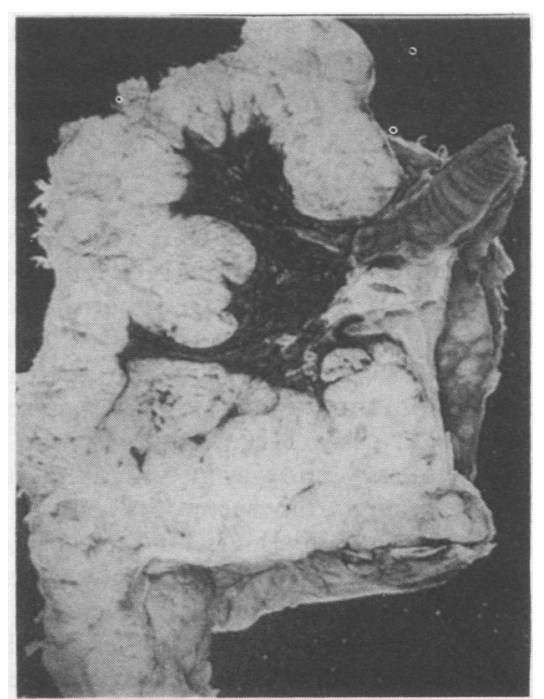

Figure 1 The original mesothelioma. 


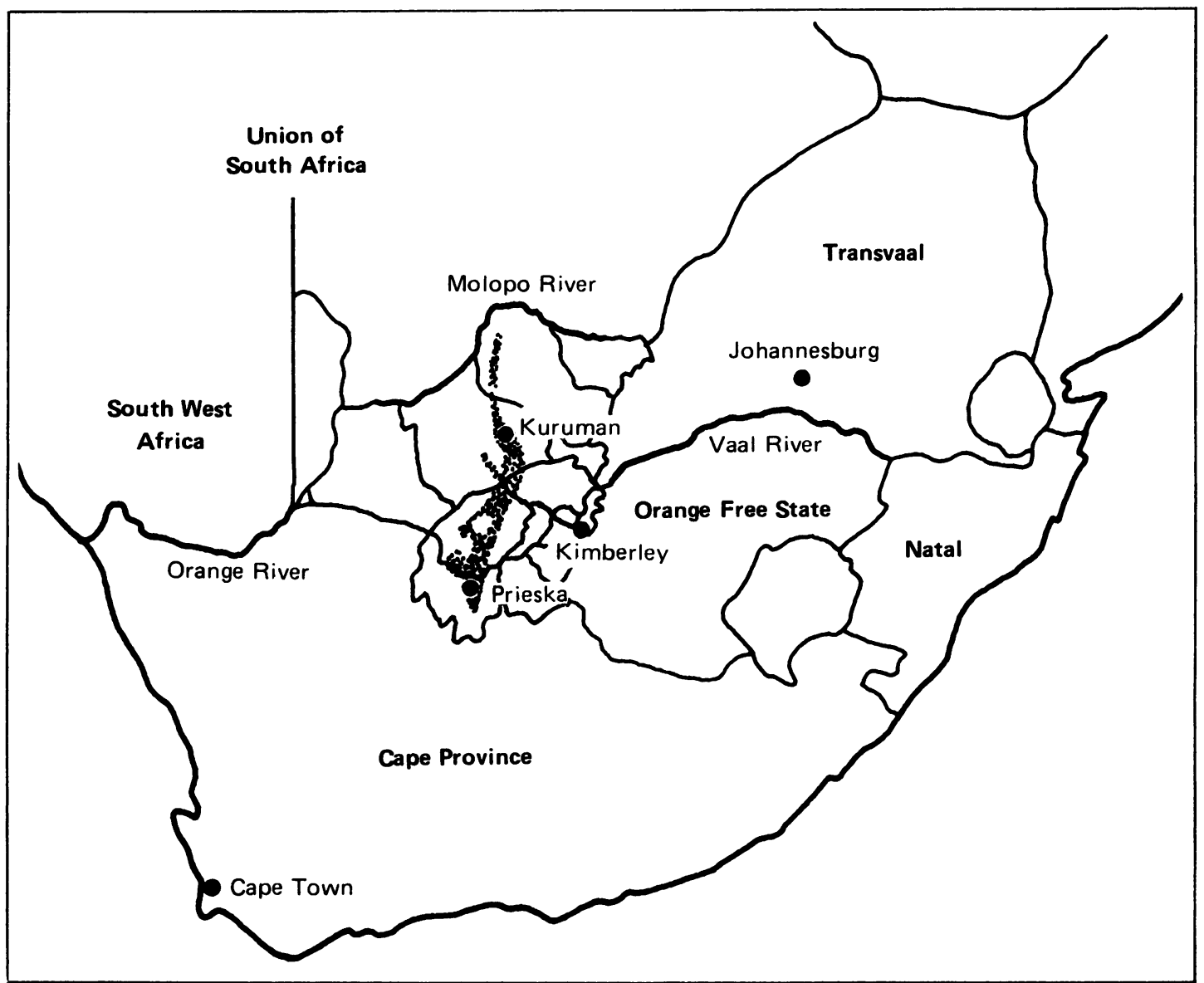

Figure 2 Map showing the location of the blue asbestos mines to the west of Kimberly.

decided to use this hospital for the treatment of tuberculosis, with Dr Sleggs in charge. The hospital received cases from an area larger than Holland, with Kimberly at the centre. As tuberculosis was endemic only the most severe cases could be admitted with many suffering from tuberculous pleurisy. Initially these cases were inevitably fatal, but with the event of such drugs as streptomycin and INH some of these cases recovered. Dr Sleggs noticed that the patients who recovered came from those cases from the eastern side, whereas the deaths continued among those coming from the western side. He then referred the western side cases for opinions to the larger centres in the country, and was informed that some of them were suffering from secondary cancer of the pleura and not tuberculosis. As Dr Sleggs said "No one suggested where the primary tumour was." $\mathrm{He}$ invited Fatti to see six of these strange cases. Fatti examined them and also looked at $x$ ray films of previous cases. He was amazed to see features identical with the case that we had presented in
Johannesburg. He returned to Johannesburg and arranged for his partner, $\mathrm{Mr}$ Paul Marchand, to take open biopsies from the cases in hospital, any further cases still alive, and future cases with similar radiological features. Paul Marchand submitted a steady flow of these so that by the end of the year we had 10 biopsy specimens, and two more necropsy specimens showing the features of mesotheliomas. Professor Paul Steiner of Chicago was visiting Johannesburg and he agreed that these were mesotheliomas.

The question then arose, as to why we were diagnosing so many cases of an extremely rare tumour. I recalled that Dr Sleggs had stated that these cases were from the west of Kimberly, and also that we had seen asbestos bodies in the lung of the first case. I therefore suggested that we should investigate the possibility that these tumours were associated with asbestos. Blue asbestos (crocidolite) was produced from a series of mines extending along the range of the Asbestos Mountains, which are 400 
miles long, starting near the Orange river and extending to the Malopo river, with the main mine being 90 miles west of Kimberly (fig 2 ).

Most of the biopsies taken by Marchand were from the parietal pleura, but a few contained a small piece of lung tissue. All these specimens were re-examined and we found a few asbestos bodies in three more cases. My hypothesis could not be supported however, from the original histories obtained from these patients, all of whom denied that they had worked with asbestos, and, indeed, their occupations were as diverse as housewives, domestic servants, cattlebreeders, farmers, a water bailiff, an insurance agent, an accountant, and an international goalkeeper! It was only subsequently that we discovered that working with asbestos carried a social stigma for both white and black people. The white patients did not like to admit to such poor financial circumstances that they had had to drive donkey wagons containing asbestos fibre to the rail heads or had had to work as unskilled labourers. The black patients regarded cobbing as women's work. Also, we learned that trade in illicit diamond selling flourished in the taverns on the asbestos fields. The diamonds were stolen in Kimberly, but to avoid the police, trading usually took place elsewhere. Therefore if you asked a patient if he had visited the asbestos mines you were suspected of having police connections.

It was not until the middle of 1958 that Paul Marchand had a patient to examine who had both asbestosis and mesothelioma. The patient also denied that he had worked with asbestos, but when Paul looked at $x$ ray film from the patient's brother, large pleural plaques were evident so, at last a history was obtained. Their father had managed a small asbestos mine and both sons had played on the dumps as children. We then started asking about environmental exposure of patients, from them or relatives, and we obtained a complete environmental and occupational history in most cases.

The most sinister of the environmental exposures was the mill and its associated tailings dumps. The villages had grown around the mills and these dumps. Many of the patients recorded living in a blue haze and the schools were established near the dumps, which proved a fatal attraction for many of the children; according to the present epidemiological work, there is still a high rate of mesotheliomas among the people who went to the village primary schools. At the end of 1961 we had seen 67 cases from the Cape asbestos fields; of these 30 had had occupational exposure and a further eight had been exposed working with asbestos outside that industry. Twenty nine had no occupational exposure, but of these 22 had been born on the Cape asbestos fields. A further nine cases had had exposure to blue asbestos industrially elsewhere in South Africa. For two cases neither a positive industrial nor environmental history could be obtained.
In the cases from the asbestos fields the average time between first exposure and development of the tumour was 44 years. The youngest patient developed a mesothelioma at the age of 20; he had been exposed as a baby when his mother carried him on her back while she was cobbing asbestos fibre.

\section{Type of asbestos and mesotheliomas}

The next problem was were these tumours associated with exposure to other types of asbestos? I had been appointed to a research fellowship in 1954 to establish whether all types of asbestos caused the same diseases. Southern Africa was the only country in the world where the three major types of asbestos-namely, crocidolite, amosite, and chrysotile were mined. Each of these fibres had been produced for at least 30 years by a large labour force. Through the South African Pneumoconiosis Bureau we were able to examine the thoracic organs of most of the asbestos miners and millers who had died in South Africa. The bureau had the radiological and clinical evidence of disease for all miners and for a significant number of men who had previously been employed in the industry. Also, we had visited the hospitals near the amosite and chrysotile mines, and had contact with the medical services supervising the mines in Southern Rhodesia (Zimbabwe) and Swaziland. We found carcinoma of the lung, asbestosis, and pleural plaques amongst the amosite miners and occasional cases of asbestosis among the chrysotile miners. Mesotheliomas were only seen in cases from the Cape asbestos fields, in those who had been exposed to blue asbestos dust either environmentally or in industry. There were, and this fact becomes more and more important as the story develops, several cases of mesothelioma in whom it was not possible to establish any history of exposure to asbestos.

By 1962 it became obvious that these investigations should be continued in the United Kingdom. In 1957 I had visited Great Britain on sabbatical leave and had discussed the early evidence of the association between exposure to blue asbestos and mesotheliomas with the authorities on occupational health and the directors of the main British asbestos companies.

Richard Doll's paper in 1955 had confirmed the increased incidence of carcinoma of the lung among asbestos workers. Industry showed little enthusiasm for the investigation of another possible neoplasm among their workers. Support came from the medical authorities, on occupational health, who thought that I should return to South Africa and obtain further evidence of the association. Support in South Africa was lukewarm. Industry was worried that my investigation would have a detrimental effect on the export of asbestos, and my medical supporters were convinced that the main research problem was the 
association between gold mining and pulmonary disability.

In spite of all the misgivings the asbestos industry in Britain and their subsidiaries in South Africa provided all the information and samples that I requested for further studies on their workers and in experimental animals. My immediate medical and scientific colleagues were convinced that the work should continue. Apart from Kit Sleggs and Paul Marchand these were Charles Theron, Gerhardt Sluis-Cremer, and Jack Harington. The director of our unit, Dr A J Orenstein was convinced enough by Dr Harold S Stewart (head of pathology at NIH Bethesda, USA), to support my studies. According to Dr Stewart this was because they had both been at Jefferson College!

By 1.961, Dr J C Gilson, director of the British Pneumoconiosis Unit was enthusiastic that the studies should continue at his unit, to see whether the findings could be corroborated in a country where workers had been exposed, in industrial situations, to a considerable amount of amphibole fibres. Therefore in 1962, I transferred to Gilson's unit with two of my senior technical staff. It soon became obvious that mesotheliomas were as prevalent among the industrial workers in Britain as they were among the miners and millers in South Africa.

The problem seemed serious enough to warrant an international investigation, which was instigated by Dr Stewart under the aegis of the International Union against Cancer. In 1964, an ad hoc committee was formed under the chairmanship of Dr John Higginson, who was director of the International Agency for Cancer Research. This committee was to report back in 1972. The summary of the situation was prepared by Dr Gilson as a series of questions and answers, which are presented below together with my personal updating of the situation as it stands in 1990.

\section{Main recommendations of the advisory committee $^{2-4}$}

(1) Q. Are all major commercial types of asbestos able to cause lung cancer?

A. 1972. Yes. Since 1964 the evidence of a causal relationship has been increased by epidemiological studies showing exposure-response relations for the incidence of lung carcinomas. The production of lung carcinomas in certain animals by all types of asbestos supports this conclusion. The epidemiological evidence in man, however, shows that there are clear differences in risk with type of fibre and nature of exposure.

A. 1990. Yes, but the exposure must have been sufficiently severe to have caused asbestosis. The incidence is greatly increased among cigarette smokers.

(2) Q. Is there evidence of an increased risk of lung carcinoma at low levels of exposure to asbestos, such as have been encountered by the general population in urban areas?

A. 1972. The evidence of an exposure-response relationship based in part on past dust measurements and in part on the type of job within the industry suggests that an excess lung cancer risk is not detectable when the occupational exposure has been low. These low occupational exposures have almost certainly been much greater than that to the public from general air pollution.

A. 1990 . No!

(3) Q. Since 1964 has the evidence relating past exposure to asbestos and mesotheliomas changed?

A. 1972. The evidence has been greatly strengthened by further prospective and retrospective mortality studies in many countries, of populations exposed to asbestos. There is evidence that all types of commercial asbestos except anthophyllite may be responsible. Evidence for an important difference in risk in different occupations and with the type of asbestos has increased. The risk is greatest with crocidolite, less with amosite, and apparently less with chrysotile. With amosite and chrysotile there appears to be a higher risk in manufacturing than in mining and milling. There is also evidence from population studies that a proportion of cases of mesothelioma have no known association with exposure to asbestos.

A. 1990. There is overwhelming evidence that crocidolite is the main fibre associated with mesotheliomas. Amosite has been associated with a few mesotheliomas in South Africa, and a few more in the United States, but these cases are minimal when compared with those caused by crocidolite. There have been cases due to exposure to tremolite, and the closely related fibres actinolite and richterite. In most cases tremolite usually occurs as a contaminant of chrysotile, and more rarely with vermiculite and talc. There is no clear evidence that exposure to uncontaminated chrysotile or anthophyllite is associated with these tumours.

It is most important to realise that there are mesotheliomas not associated with exposure to asbestos. More than 100 cases were described as occurring in man before 1900, and other cases appear in all subsequent epidemiological studies. Most of these cases are cryptogenic but a few have been associated with previous radiotherapy.

(4) $Q$. Is there evidence of an increased risk of mesothelial cancers at low levels of exposure to asbestos, such as have been encountered by the general population in urban areas?

A. 1972. There is evidence of an association of mesothelial tumours with air pollution in the neighbourhood of crocidolite mines and of factories using mixtures of asbestos fibre types. The evidence relates to conditions many years ago. There is 
evidence of no excess risk of mesotheliomas from asbestos air pollution which has existed in the neighbourhood of chrysotile and amosite mines. There are reported differences on incidence of mesothelioma between urban and rural areas, the causes of which have not been established. There is no evidence of risk to the general public at present.

A. 1990. There is no further evidence about the comparison between urban and rural areas. There is definitely no risk to the general public except when buildings containing crocidolite are being demolished. The wholesale removal of chrysotile from buildings is absurd.

(5) Q. Since 1964 has the evidence changed on the importance of other factors such as cigarette smoking, waxes, oils, and trace elements as contributory factors to the cancer risk?

A. 1972. The evidence has accumulated indicating:

(a) The cigarette is an important factor enhancing the lung cancer risk in asbestos-exposed workers, in both men and women. Asbestos workers have especially strong grounds for giving up smoking to protect their health. No association has been demonstrated between cigarette smoking and mesotheliomas.

(b) Animal experiments designed thus far to test the importance of waxes and oils as contributory factors in the production of mesothelioma have shown these contaminants are unlikely to be relevant.

(c) From animal experiments there are no good clues suggesting that trace elements are likely to be a major factor in the production of asbestos cancers.

A. 1990. (a) Cigarette smoking is the major factor in enhancing the lung cancer risk in asbestos workers.

(b and c) No further evidence has been obtained.

(6) Q. What other types of cancer are related to exposure to asbestos?

A. 1972. Prospective surveys of occupational groups exposed to asbestos have in general shown a small excess risk of some other types of cancer (in addition to bronchial and mesothelial), especially those of the gastro-intestinal tract. The excess of these tumours is relatively small compared with that for bronchial cancer. Evidence for an association with ovarian tumours has not been supported by the first large mortality survey of women previously exposed to asbestos.

A. 1990. Slight evidence exists showing that incidence of tumours of the upper respiratory tract may be increased. There is little support for an increase of tumours of the gastrointestinal tract. The situation concerning carcinoma of the ovary is dif- ficult. The problem is where does the surface of the ovary end and where does the peritoneal mesothelium begin? The situation is further complicated by some groups in the United States who now describe mesotheliomas of the ovary.

(7) $Q$. Is there evidence of an increased risk of cancer resulting from asbestos fibres present in water, beverages, food, or in fluids used for the administration of drugs?

A. 1972. Such evidence as there is does not indicate any risk.

A. 1990 . No.

(8) $Q$. Is there any risk of lung fibrosis from low levels of exposure to asbestos such as have been encountered by the general population in urban areas?

A. 1972. There is at present no evidence of lung damage by asbestos to the general public, the amount of asbestos in the lungs of the general public is very small, compared with those occupationally exposed. It is greatest where asbestos is mined or worked and lowest in the rural areas.

A. 1990. A risk exists to bystanders or domestic associates of asbestos workers, who do not have a change of clothing and adequate washing facilities at work, after working with asbestos, particularly crocidolite. No risk exists to the public at large.

(9) $Q$. Has the relationship between asbestos exposure and the development of pleural plaques been established?

A. 1972. Pleural plaques have been associated with past exposure to all commercial types of asbestos. But additional factors, other than asbestos itself, are involved. The plaques may remain fibrous or become calcified. Not all pleural plaques are associated with asbestos.

A. 1990. Pleural plaques that are symmetrical and bilateral, are associated with exposure to amphibole fibres or chrysotile contaminated with an amphibole.

1 Wagner JC, Sleggs CA, Marchand P. Diffuse pleural mesotheliomas and asbestos exposure in the north western Cape Province. Br J Ind Med 1960;17:260-71.

2 Report of the advisory committee on asbestos cancers to the director of the International Agency for Research on Cancer. In: Brogofsky P, Gilson JC, Timbrell V, Wagner JC, eds. Biological effects of asbestos. Lyon: International Agency for Research on Cancer, 1973:342-3. (IARC publ No 8.)

3 Report and recommendations of the working group on asbestos and cancer (covered under the auspices of the geographical pathology "committee of the International Union against Cancer). Br J Ind Med 1965;22:165.

4 Biological effects of asbestos. Report of the advisory committee on asbestos cancers to the director of the International Agency for Research on Cancer. Ann Occup Hyg 1973;16:9-17.

5 Martiny O. Report on a case of mesothelioma. Proceedings of the Transvaal Medical Officers Association 1956;35:355-63.

Accepted 10 December 1990 